\title{
FAKTOR-FAKTOR PENGARUH KEBERHASILAN IMPLEMENTASI PROGRAM UPAYA KHUSUS PENINGKATAN PRODUKSI PADI DI KABUPATEN BANYUMAS
}

\author{
Aspri Budi Oktavianto \\ Dosen Program Studi Ilmu Administrasi Negara, Universitas Wijayakusuma, Purwokerto \\ Email: aspribudi@gmail.com
}

\begin{abstract}
Abstrak
Kebijakan publik sektor pertanian telah lama dibuat di Indonesia mengingat sebagian besar mata pencaharian masyarakat didasarkan pada sektor pertanian. Pertanian memiliki peran penting dalam menyediakan makanan dan bahan baku industri, berkontribusi terhadap produk domestik bruto (PDB), menghasilkan devisa, menyerap tenaga kerja, sumber pendapatan pertama bagi masyarakat pedesaan, penyedia bahan pakan dan bioenergi, dan mengurangi emisi gas rumah kaca . Program Upaya Khusus (Upsus) untuk Produksi Beras di Kabupaten Banyumas diharapkan dapat meningkatkan ketersediaan beras dan stabilitas harga. Faktor-faktor yang dianggap berpengaruh adalah respons kelompok sasaran, kemampuan organisasi pelaksana, dan daya dukung lingkungan. Untuk menganalisis dan menggambarkan besarnya pengaruh respon kelompok sasaran, kemampuan organisasi pelaksana, dan daya dukung lingkungan terhadap keberhasilan pelaksanaan program upaya khusus untuk meningkatkan produksi beras di kabupaten Banyumas, baik secara parsial maupun sebagai senyawa, pendekatan kuantitatif dengan jenis penelitian survei dengan 83 responden digunakan. Dari hasil penelitian dan analisis data, dapat disimpulkan bahwa ada pengaruh yang signifikan terhadap respon kelompok sasaran, kemampuan organisasi pelaksana, dan daya dukung lingkungan terhadap keberhasilan pelaksanaan program upaya khusus untuk meningkatkan produksi beras dengan arah positif untuk pengukuran secara individu dan bersama-sama.
\end{abstract}

Kata Kunci: Daya Dukung Lingkungan, Keberhasilan Implementasi, Kemampuan Organisasi Pelaksana, Respon Kelompok Sasaran.

\section{Abstract}

Agricultural sector public policies have long been made in Indonesia given that most of the people's livelihoods are based on the agricultural sector. Agriculture has an important role in providing food and industrial raw materials, contributing to gross domestic product (GDP), producing foreign exchange, absorbing labor, the first source of income for rural communities, providers of feed ingredients and bioenergy, and reducing greenhouse gas emissions. The Special Efforts Program (Upsus) for Rice Production in Banyumas Regency is expected to increase rice availability and price stability. The factors considered influential are the response of the target group, the ability of the implementing organization, and the carrying capacity of the environment. To analyze and describe the magnitude of the effect of the response of the target group, the ability of the implementing organization, and the environmental carrying capacity on the successful implementation of a special effort program to increase rice production in Banyumas district, both partially and as a compound, a quantitative approach with the type of survey research with 83 respondents was used. From the results of research and data analysis, it can be concluded that there is a significant effect on the response of the target group, the ability of the implementing organization, and the carrying capacity of the environment on the successful implementation of a special effort program to increase rice production with a positive direction for measurement individually and jointly.

Keywords: Environmental Carrying Capacity, Successful Implementation, Implementing Organization Capability, Response Target Group. 


\section{PENDAHULUAN}

Kebijakan publik dapat dikatakan sebagai suatu produk pemerintah yang membutuhkan implementasi agar tujuan yang hendak dicapai menjadi nyata. Tanpa implementasi, maka kebijakan yang telah disusun oleh perumus kebijakan hanya akan sia-sia. Kebijakan hanya akan menjadi dokumen tertulis yang dianggap sempurna tanpa melihat kenyataan di lapangan. Setelah kebijakan diimplementasikan maka akan terlihat apakah kebijakan yang telah dibuat telah mencapai tujuan yang telah ditentukan atau belum. Apabila belum mampu mencapai tujuan yang ditentukan, maka ketika kebijakan yang diimplementasi akan memiliki pilihan untuk dilanjutkan, diperbaiki, atau dihentikan.

Program Upaya Khusus peningkatan produksi Padi, Jagung, dan Kedelai 2015 merupakan keberlanjutan dari program sebelumnya yaitu program Ketahanan Pangan tahun 2013. Program Ketahanan Pangan tahun 2013 dan Program Upsus tahun 2015 merupakan kerjasama antara Direktorat Jenderal Sarana dan Prasarana Pertanian dengan TNI Angkatan Darat. Program Upaya Khusus (Upsus) Peningkatan Produksi Padi di Kabupaten Banyumas diharapkan mampu meningkatkan ketersediaan beras dan kestabilan harga. Penelitian tentang keberhasilan implemetasi telah banyak oleh peneliti. Beberapa diantaranya Budiani (2007); Yus (2011); Nasila (2014); Sanjaya (2014); Rindayani (2014); Trisnawati (2016); dan Daryanto (2016).

Beberapa penelitian telah memberikan gambaran tentang keberhasilan implementasi di Indonesia. Ada penelitian yang menggambarkan tentang implementasi dan adapula penelitian yang melihat pengaruh variabel bebas terhadap keberhasilan implementasi. Penelitian ini mencoba mengungkap Pengaruh Respon Kelompok Sasaran, Kemampuan Organisasi Pelaksana, Dan Daya Dukung Lingkungan Terhadap Keberhasilan Implementasi Program yang diungkapkan oleh Smith, penelitian ini merupakan replikasi dari penelitian yang telah dilakukan oleh Trisnawati (2016) yang juga menggunakan dimensi dari Smith.

\section{METODE PENELITIAN}

Penelitian ini mengacu pada metode penelitian survei. Selanjutnya penelitian ini bermaksud untuk melakukan penjelasan (explanatory atau confirmatory) yakni menjelaskan hubungan kausal antara variabel-variabel. Populasi dalam penelitian ini adalah gabungan kelompok tani (gapoktan) yang mendapatkan program upaya khusus (Upsus) di Kabupaten Banyumas. Jumlah populasi dalam penelitian ini adalah 331 kelompok. Penarikan sampel dalam penelitian ini dilakukan dengan teknik cluster random sampling yang berjumlah 83 orang.

Tabel 1. Matriks Definisi

\begin{tabular}{lll}
\hline \multicolumn{1}{c}{ Variabel } & \multicolumn{1}{c}{ Indikator } & \multicolumn{1}{c}{ Item Pertanyaan } \\
\hline Keberhasilan & 1.Tepat Kebijakan & a. Ketepatan tujuan kebijakan \\
Implementasi & & b. Ketepatan hasil kebijakan \\
\hline
\end{tabular}




\begin{tabular}{|c|c|c|}
\hline \multirow[t]{4}{*}{ Program (Y) } & 2. Tepat Pelaksanaan & $\begin{array}{l}\text { a. Kesiapan aparat pelaksana } \\
\text { b. Daya tanggap aparat pelaksana }\end{array}$ \\
\hline & 3. Tepat Target & $\begin{array}{l}\text { a. Ketepatan objek sasaran kebijakan } \\
\text { b. Kesadaran objek sasaran kebijakan }\end{array}$ \\
\hline & 4. Tepat Lingkungan & $\begin{array}{l}\text { a. Kesiapan gapoktan terhadap program } \\
\text { b. Daya dukung gapoktan terhadap program }\end{array}$ \\
\hline & 5. Tepat Proses & $\begin{array}{l}\text { a. Kesesuaian peran gapoktan dalam } \\
\text { melaksanakan proses implementasi } \\
\text { b. Kesesuaian proses implementasi program } \\
\text { dengan panduan dan waktu pelaksanaan }\end{array}$ \\
\hline \multirow{4}{*}{$\begin{array}{l}\text { Respon Kelompok } \\
\text { Sasaran (X1) }\end{array}$} & 1. Sikap yang & a. Sosialisasi program kepada gapoktan \\
\hline & ditunjukkan & b. Pengetahuan terhadap program \\
\hline & anggota gapoktan & $\begin{array}{l}\text { c. Respon anggota gapoktan atas program } \\
\text { tersebut }\end{array}$ \\
\hline & $\begin{array}{l}\text { 2. Partisipasi dari } \\
\text { anggota gapoktan } \\
\text { (perencanaan, } \\
\text { pelaksanaan, } \\
\text { monitoring, dan } \\
\text { evaluasi) }\end{array}$ & $\begin{array}{l}\text { a. Partisipasi anggota gapoktan dalam } \\
\text { membuat Rencana Definitif Anggaran } \\
\text { b. Keterlibatan anggota gapoktan dalam } \\
\text { program tersebut }\end{array}$ \\
\hline \multirow{6}{*}{$\begin{array}{l}\text { Kemampuan } \\
\text { Organisasi } \\
\text { Pelaksana (X2) }\end{array}$} & 1. Kemampuan & a. Kemampuan interaksi anggota gapoktan \\
\hline & intelektual & dan aparat pelaksana dengan lingkungan \\
\hline & & $\begin{array}{l}\text { b. Peran dan fungsi babinsa dan penyuluh } \\
\text { terkait program }\end{array}$ \\
\hline & & $\begin{array}{l}\text { c. Menjelaskan perubahan sebelum dan } \\
\text { sesudah program }\end{array}$ \\
\hline & 2. Kemampuan fisik & $\begin{array}{ll}\text { a. Ketersediaan fasilitas penunjang program } \\
\text { b. Kemampuan babinsa dan gapoktan dalam } \\
\text { memperbaiki fasilitas yang rusak }\end{array}$ \\
\hline & & $\begin{array}{l}\text { c. Upaya yang dilakukan oleh babinsa dan } \\
\text { penyuluh terkait program }\end{array}$ \\
\hline \multirow{4}{*}{$\begin{array}{l}\text { Daya Dukung } \\
\text { Lingkungan (X3) }\end{array}$} & 1. Dukungan sosial & a. Peraturan yang mendukung program \\
\hline & & $\begin{array}{l}\text { b. Partisipasi babinsa, penyuluh dan } \\
\text { pemerintah desa terkait program } \\
\text { c. Keterlibatan masyarakat terkait program } \\
\text { d. Tanggapan masyarakat terkait program }\end{array}$ \\
\hline & 2. Kondisi fisik & a. Aksesbilitas lahan pertanian \\
\hline & & b. Kol \\
\hline
\end{tabular}

\section{HASIL DAN PEMBAHASAN}

HASIL PENELITIAN

\section{Pengaruh Respon Kelompok Sasaran terhadap Keberhasilan Implementasi}

Pembahasan pengujian hipotesis pertama dilakukan dengan melihat hubungan antara Respon Kelompok Sasaran (X1) dengan Keberhasilan Implementasi (Y). Analisis hubungan dilakukan dengan analisis Kendall Tau-b yang menunjukkan hasil berikut ini.

Tabel 2. Korelasi Antara Respon Kelompok Sasaran (X1) terhadap Keberhasilan Implementasi Program Upsus (Y)

\begin{tabular}{lllcc}
\hline & & $\mathrm{X} 1$ & $\mathrm{Y}$ \\
\hline Kendall's tau_b & $\mathrm{X} 1$ & Correlation coefficient & 1.00 & $504 "$ \\
& & Sig. (2-tailed) &. & .000 \\
& $\mathrm{~N}$ & 83 & 83 \\
\cline { 2 - 4 } & $\mathrm{Y}$ & Correlation coefficient & $504^{\prime \prime}$ & 1.00 \\
& Sig. (2-tailed) & .000 &. \\
& $\mathrm{~N}$ & 83 & 83 \\
\hline
\end{tabular}

Sumber: Data primer diolah, 2017

Tabel korelasi Kendall Tau-b Respon Kelompok Sasaran (X1) terhadap Keberhasilan Implementasi $(\mathrm{Y})$ menunjukkan bahwa terjadi korelasi sebesar 0.504 dengan menunjukkan 
hubungan yang positif. Artinya semakin baik respon kelompok sasaran maka akan semakin meningkatkan keberhasilan implementasi dan sebaliknya, semakin buruk respon kelompok sasaran maka keberhasilan implementasi akan semakin rendah. Hasil uji korelasi tersebut diperkuat dengan membandingkan nilai sig. (2-tailed) dengan $\alpha(0,05)$. Berdasarkan perhitungan statistik menunjukkan bahwa nilai sig 0,001<0,05. Dengan demikian, korelasi antara variabel respon kelompok sasaran dengan keberhasilan implementasi sebesar 0.504 adalah signifikan. Selanjutnya untuk menguji pengaruh variabel respon kelompok sasaran (X1) terhadap keberhasilan implementasi (Y) digunakan analisis regresi ordinal yang hasilnya ditampilkan sebagai berikut.

Tabel 3. Model Fitting Information Variabel Respon Kelompok Sasaran terhadap Keberhasilan Implementasi Program Upsus

\begin{tabular}{lcccc}
\hline Model & -2 Log Likelihood & Chi-Square & df & Sig. \\
\hline Intercept Only & 47.107 & & & \\
Final & 22.480 & 24.628 & 2 & .000 \\
\hline
\end{tabular}

Sumber: Data primer diolah, 2017

Tabel model fitting information memberikan informasi bahwa respon kelompok sasaran (X1) berpengaruh terhadap keberhasilan implementasi (Y) sebesar 47.107 dan signifikansi pada taraf kepercayaan 0,001 $<0,05$. Model ini berarti dapat digunakan untuk memprediksi pengaruh variabel respon kelompok sasaran terhadap keberhasilan implementasi. Artinya, setiap kenaikan satu unit sebesar 47.107 pada variabel respon kelompok sasaran maka akan diikuti pula kenaikan satu unit sebesar 47.107 pada variabel keberhasilan implementasi. Selanjutnya untuk mengetahui berapa sumbangan variabel respon kelompok sasaran (X1) terhadap keberhasilan implementasi (Y) digunakan Pseudo R-Square yang hasilnya ditampilkan pada tabel berikut ini.

Tabel 4. Pseudo R-Square Variabel Respon Kelompok Sasaran terhadap Keberhasilan Implementasi Program Upsus

\begin{tabular}{lr}
\hline Cox and Snell & .257 \\
Nagelkerke & .301 \\
McFadden & .155 \\
\hline
\end{tabular}

Sumber: Data primer diolah

Tabel Pseudo R-Square menunjukkan sejauhmana variabel respon kelompok sasaran mampu menjelaskan variabel keberhasilan implementasi. Berdasarkan nilai Nagelkerke sebesar 0.301 artinya variabel respon kelompok sasaran mampu menjelaskan variabel keberhasilan implementasi sebesar 30.1 persen, sedangkan sisanya 69.9 persen dijelaskan oleh variabel lain.

\section{Pengaruh Kemampuan Organisasi Pelaksana terhadap Keberhasilan Implementasi}

Pembahasan pengujian hipotesis kedua dilakukan sama dengan sebelumnya, yakni akan diawali dengan pembahasan hasil hubungan antara Kemampuan Organisasi Pelaksana (X2) dengan Keberhasilan Implementasi (Y) dengan analisis Kendall Tau-b dengan hasil berikut ini. 
Tabel 5. Korelasi antara Kemampuan Organisasi Pelaksana (X2) dengan Keberhasilan Implementasi Program Upsus (Y)

\begin{tabular}{cclcc}
\hline & & $\mathrm{X} 2$ & $\mathrm{Y}$ \\
\hline Kendall's tau_b & $\mathrm{X} 2$ & Correlation coefficient & 1.00 & $464 "$ \\
& & Sig. (2-tailed) &. & .000 \\
& $\mathrm{~N}$ & 83 & 83 \\
\cline { 2 - 4 } & $\mathrm{Y}$ & Correlation coefficient & $464 "$ & 1.00 \\
& & Sig. (2-tailed) & .000 &. \\
& $\mathrm{~N}$ & 83 & 83 \\
\hline
\end{tabular}

Sumber: Data primer diolah, 2017

Tabel korelasi kendall tau- $b$ memberikan informasi bahwa koefisien korelasi kendall taub antara variabel kemampuan organisasi pelaksana (X2) dengan Keberhasilan Implementasi (Y) sebesar 0.464 dengan menunjukkan hubungan yang positif. Artinya semakin baik kemampuan organisasi pelaksana maka akan semakin meningkatkan keberhasilan implementasi dan juga sebaliknya, semakin buruk kemampuan organisasi pelaksana maka keberhasilan implementasi akan semakin menurun. Hasil uji korelasi tersebut juga diperkuat dengan membandingkan nilai sig. (2-tailed) dengan $\alpha(0,05)$. Berdasarkan perhitungan statistik menunjukkan bahwa nilai sig 0,001<0,05. Dengan demikian korelasi antara variabel kemampuan organisasi pelaksana dengan keberhasilan implementasi sebesar 0.464 adalah signifikan. Selanjutnya untuk menguji pengaruh variabel kemampuan organisasi pelaksana dengan keberhasilan implementasi dengan analisis regresi ordinal yang hasilnya ditampilkan sebagai berikut.

Tabel 6. Model Fitting Information Variabel Kemampuan Organisasi Pelaksana terhadap Keberhasilan Implementasi Program Upsus

\begin{tabular}{lrrrr}
\hline Model & -2 Log Likelihood & Chi-Square & df & \multicolumn{1}{c}{ Sig. } \\
\hline Intercept Only & 35.997 & & & \\
Final & 13.389 & 22.608 & 2 & .000 \\
\hline
\end{tabular}

Sumber: Data primer diolah, 2017

Tabel model fitting information memberikan informasi bahwa kemampuan organisasi pelaksana (X2) berpengaruh terhadap keberhasilan implementasi (Y) sebesar 35.997 dan signifikansi pada taraf kepercayaan 0,001 < 0,05. Model ini berarti dapat digunakan untuk memprediksi pengaruh variabel kemampuan organisasi pelaksana terhadap keberhasilan implementasi. Artinya, setiap kenaikan satu unit sebesar 35.997 pada variabel kemampuan organisasi pelaksana maka akan diikuti pula kenaikan satu unit sebesar 35.997 pada variabel keberhasilan implementasi. Selanjutnya untuk mengetahui berapa sumbangan variabel kemampuan organisasi pelaksan (X2) terhadap keberhasilan implementasi $(\mathrm{Y})$ digunakan Pseudo R-Square yang hasilnya ditampilkan pada tabel berikut ini

Tabel 7. Pseudo R-Suare antara Variabel Kemampuan Organisasi Pelaksana terhadap Keberhasilan Implementasi Program Upsus

\begin{tabular}{ll}
\hline Cox and Snell & .238 \\
Nagelkerke & .279 \\
McFadden & .142 \\
\hline
\end{tabular}

Sumber: Data primer diolah, 2017 
Tabel Pseudo R-Square menunjukkan sejauhmana variabel kemampuan organisasi pelaksana mampu menjelaskan variabel keberhasilan implementasi. Berdasarkan nilai Nagelkerke sebesar 0.279 artinya variabel kemampuan organisasi pelaksana mampu menjelaskan variabel keberhasilan implementasi sebesar 27.9 persen, sedangkan sisanya 72.1 persen dijelaskan oleh variabel lain.

\section{Pengaruh Daya Dukung Lingkungan terhadap Keberhasilan Implementasi}

Pembahasan pengujian hipotesis ketiga dilakukan sama dengan sebelumnya, yakni akan diawali dengan pembahasan hasil hubungan antara Daya Dukung Lingkungan (X3) dengan Keberhasilan Implementasi (Y) dengan analisis Kendall Tau-b dengan hasil berikut ini.

Tabel 8. Korelasi antara Daya Dukung Lingkungan (X3) terhadap Keberhasilan Implementasi Program Upsus (Y)

\begin{tabular}{lllcc}
\hline & & X3 & Y \\
\hline Kendall's tau_b & X3 & Correlation coefficient & 1.00 & $346^{\prime \prime}$ \\
& & Sig. (2-tailed) &. & .000 \\
& N & 83 & 83 \\
& Y & Correlation coefficient & $346^{\prime \prime}$ & 1.00 \\
& & Sig. (2-tailed) & .000 &. \\
& & N & 83 & 83 \\
\hline
\end{tabular}

Sumber: Data primer diolah, 2017

Tabel korelasi kendall tau-b memberikan informasi bahwa koefisien korelasi kendall tau$b$ antara variabel daya dukung lingkungan (X3) dengan Keberhasilan Implementasi (Y) sebesar 0.346 dengan menunjukkan hubungan yang positif. Artinya semakin baik kemampuan organisasi pelaksana maka akan semakin meningkatkan keberhasilan implementasi dan juga sebaliknya, semakin buruk kemampuan organisasi pelaksana maka keberhasilan implementasi akan semakin menurun. Hasil uji korelasi tersebut juga diperkuat dengan membandingkan nilai sig. (2-tailed) dengan $\alpha(0,05)$. Berdasarkan perhitungan statistik menunjukkan bahwa nilai sig 0,001 $<0,05$. Dengan demikian korelasi antara variabel daya dukung lingkungan dengan keberhasilan implementasi sebesar 0.346 adalah signifikan. Selanjutnya untuk menguji pengaruh variabel daya dukung lingkungan dengan keberhasilan implementasi dengan analisis regresi ordinal yang hasilnya ditampilkan sebagai berikut.

Tabel 9. Model Fitting Information Variabel Daya Dukung Lingkungan terhadap Keberhasilan Implementasi Program Upsus

\begin{tabular}{lcccc}
\hline Model & -2 Log Likelihood & Chi-Square & df & Sig. \\
\hline Intercept Only & 42.284 & & & \\
Final & 21.442 & 20.841 & 2 & .000 \\
\hline
\end{tabular}

Sumber: Data primer diolah, 2017

Tabel model fitting information memberikan informasi bahwa daya dukung lingkungan (X3) berpengaruh terhadap keberhasilan implementasi (Y) sebesar 42.284 dan signifikansi pada taraf kepercayaan 0,001 $<0,05$. Model ini berarti dapat digunakan untuk memprediksi pengaruh variabel daya dukung lingkungan terhadap keberhasilan implementasi. Artinya, setiap kenaikan satu unit sebesar 42.284 pada variabel daya dukung lingkungan maka akan 
diikuti pula kenaikan satu unit sebesar 42.284 pada variabel keberhasilan implementasi. Selanjutnya untuk mengetahui berapa sumbangan variabel daya dukung lingkungan (X3) terhadap keberhasilan implementasi (Y) digunakan Pseudo R-Square yang hasilnya ditampilkan pada tabel berikut.

Tabel 10. Pseudo R-Square Variabel Daya Dukung Lingkungan terhadap Keberhasilan Implementasi Program Upsus

\begin{tabular}{ll}
\hline Cox and Snell & .222 \\
Nagelkerke & .260 \\
McFadden & .131 \\
\hline
\end{tabular}

Sumber: Data primer diolah, 2017

Tabel Pseudo R-Square menunjukkan sejauhmana variabel daya dukung lingkungan mampu menjelaskan variabel keberhasilan implementasi. Berdasarkan nilai Nagelkerke sebesar 0.260 artinya variabel kemampuan organisasi pelaksana mampu menjelaskan variabel keberhasilan implementasi sebesar 26 persen, sedangkan sisanya 74 persen dijelaskan oleh variabel lain.

\section{Pengaruh Respon Kelompok Sasaran, Kemampuan Organisasi Pelaksana, dan Daya Dukung Lingkungan terhadap Keberhasilan Implementasi}

Pada pengujian hipotesis keempat sedikit berbeda dengan pengujian sebelumnya dimana yang pertama untuk mengetahui korelasi secara bersamaan antara respon kelompok sasaran, kemampuan organisasi pelaksana dan daya dukung lingkungan terhadap keberhasilan implementasi program Upsus dilakukan dengan mencari koefisien Konkordansi Kendall W. Hubungan secara bersama-sama antara respon kelompok sasaran, kemampuan organisasi pelaksana, dan daya dukung lingkungan terhadap implementasi program Upsus ditampilkan pada tabel berikut ini.

Tabel 11. Korelasi secara Bersama-sama Respon Kelompok Sasaran, Kemampuan Organisasi Pelaksana, dan Daya Dukung Lingkungan terhadap Keberhasilan Implementasi

\begin{tabular}{lr}
\hline N Kendall's Wa & 83 \\
Chi-Square & .084 \\
Df & 20.869 \\
Asymp. Sig. & 3 \\
\hline
\end{tabular}

Sumber: Data primer diolah, 2017

Tabel di atas menjelaskan bahwa jumlah responden sebanyak 83 yang dianalisis dan koefisien Konkordansi Kendall $W$ sebesar 0.084 dengan arah hubungan yang positif. Artinya semakin baik respon kelompok sasaran, kemampuan organisasi pelaksana, dan daya dukung lingkungan maka akan meningkatkan keberhasilan implementasi program Upsus, dan sebaliknya semakin buruk respon kelompok sasaran, kemampuan organisasi pelaksana, dan daya dukung lingkungan maka akan keberhasilan implementasi akan semakin menurun. Hasil uji korelasi diperkuat dengan membandingkan nilai Asymp. sig. (2-tailed) dengan $\alpha(0.05)$. Nilai Asymp.sig. $0.000<0.05$ artinya korelasi secara bersama-sama antara respon kelompok sasaran, kemampuan organisasi pelaksana, dan daya dukung lingkungan terhadap 
keberhasilan implementasi program Upsus sebesar 0.084 adalah signifikan. Selanjutnya untuk menguji pengaruh secara bersama-sama antara respon kelompok sasaran, kemampuan organisasi pelaksana, dan daya dukung lingkungan terhadap keberhasilan implementasi program Upsus digunakan analisis regresi ordinal yang hasilnya ditampilkan berikut ini.

Tabel 12. Model Fitting Information secara Bersama-sama Respon Kelompok Sasaran, Kemampuan Organisasi Pelaksana, dan Daya Dukung Lingkungan terhadap Keberhasilan Implementasi

\begin{tabular}{|c|c|c|c|c|}
\hline Model & -2 Log Likelihood & Chi-Square & $\mathrm{df}$ & Sig. \\
\hline Intercept Only & 102.594 & & & \\
\hline Final & 54.738 & 47.857 & 2 & .000 \\
\hline
\end{tabular}

Sumber: Data primer diolah, 2017

Tabel model fitting information menunjukkan pengaruh secara bersama-sama antara respon kelompok sasaran (X1), kemampuan organisasi pelaksana (X2), dan daya dukung lingkungan (X3) terhadap keberhasilan implementasi program Upsus (Y) diperoleh koefisien regresi ordinal sebesar 102.594 dan signifikan pada taraf 0.000 . Model ini berarti dapat digunakan untuk memprediksi pengaruh secara bersama-sama antara respon kelompok sasaran, kemampuan organisasi pelaksana, dan daya dukung lingkungan terhadap keberhasilan implementasi program Upsus. Artinya setiap kenaikan satu unit sebesar 102.594 pada variabel respon kelompok sasaran, kemampuan organisasi pelaksana, dan daya dukung lingkungan maka akan diikuti pula kenaikan satu unit sebesar 102.594 pada variabel keberhasilan implementasi program Upsus. Selanjutnya, untuk mengetahui berapa besaran sumbangan variabel respon kelompok sasaran, kemampuan organisasi pelaksana, dan daya dukung lingkungan terhadap keberhasilan implementasi program Upsus digunakan Pseudo RSquare, yang ditampilkan pada tabel berikut.

Tabel 13. Pseudo R-Square secara Bersama-sama Respon Kelompok Sasaran, Kemampuan Organisasi Pelaksana, dan Daya Dukung Lingkungan terhadap Keberhasilan Implementasi

\begin{tabular}{ll}
\hline Cox and Snell & .438 \\
Nagelkerke & .514 \\
McFadden & .301 \\
\hline
\end{tabular}

Sumber: Data primer diolah, 2017

Tabel Pseudo R-Square menunjukkan sejauh mana variabel respon kelompok sasaran, kemampuan organisasi pelaksana, dan daya dukung lingkungan mampu menjelaskan variabel keberhasilan implementasi program Upsus. Berdasarkan nilai Negelkerke sebesar 0.514 artinya variabel respon kelompok sasaran, kemampuan organisasi pelaksana, dan daya dukung lingkungan mampu menjelaskan keberhasilan implementasi program Upsus sebesar 51.4 persen, sedangkan 48.6 persen dipengaruhi oleh faktor lain yang tidak diteliti. 


\section{PEMBAHASAN}

\section{Pengaruh Respon Kelompok Sasaran terhadap Keberhasilan Implementasi}

Hasil penelitian menunjukkan diterimanya hipotesis pertama yakni ada pengaruh yang positif dan signifikan antara respon kelompok sasaran terhadap keberhasilan implementasi program upaya khusus peningkatan produksi padi di Kabupaten Banyumas. variabel respon kelompok sasaran dapat menjelaskan keberhasilan implementasi sebesar 30.1 Persen.

Hasil penelitian menunjukkan bahwa respon kelompok sasaran berpengaruh terhadap keberhasilan implementasi program. Sikap dan tanggapan dari kelompok sasaran merupakan perwujudan dari seberapa besar manfaat atau dukungan dari kelompok sasaran. Peter dan deLeon (2004) menyatakan bahwa keterlibatan kelompok sasaran merupakan bagian penting dari keberhasilan implementasi. Khariza (2015: 5) menemukan bahwa dukungan kelompok sasaran berupa keinginan agar program Jaminan Kesehatan Nasional untuk tetap dilanjutkan karena sangat membantu pelayanan. Selain itu, penelitian ini mendukung penelitian Budiani (2007) dan Yus (2011) yang menemukan bahwa ketepatan kelompok sasaran akan berpengaruh terhadap pelaksanaan program karena ketepatan kelompok sasaran akan mempengaruhi respon yang diberikan oleh kelompok sasaran.

\section{Pengaruh Kemampuan Organisasi Pelaksana terhadap Keberhasilan Implementasi}

Hasil penelitian menemukan bahwa terdapat pengaruh yang positif dan signifikan antara kemampuan organisasi pelaksana terhadap keberhasilan implementasi sebesar 0.464 . Berdasarkan hasil uji regresi ordinal, kemampuan organisasi pelaksana mampu menjelaskan keberhasilan implementasi sebesar 27.9 persen. Hal ini berarti kemampuan organisasi pelaksana berpengaruh secara positif dan signifikan terhadap keberhasilan implementasi program Upsus. Hal ini mendukung apa yang diungkapkan oleh Smith (1973) bahwa adanya kemampuan organisasi pelaksana yang baik akan mempengaruhi keberhasilan implementasi program. Begitupula dengan pendapat Hjern, dkk (1978) bahwa program yang sukses sangat dipengaruhi oleh kemampuan individu di dalam organisasi pelaksana.

Penelitian ini juga mendukung penelitian yang dilakukan oleh Nurharjadmo (2008) yang menemukan bahwa sikap pelaksana dan sasaran program Implementasi Kebijakan Sistem Ganda di Sekolah Kejuruan cukup baik menyebabkan keberhasilan program ini, para pelaksana baik komponen sekolah maupu institusi pasangan telah melaksanakan apa yang menjadi kewajibannya dengan baik.

\section{Pengaruh Daya Dukung Lingkungan terhadap Keberhasilan Implementasi}

Berdasarkan hasil pengujian hipotesis ditemukan bahwa daya dukung lingkungan berpengaruh secara positif dan signifikan sebesar 0.346. Berdasarkan uji regresi ordinal, daya dukung lingkungan mampu menjelaskan keberhasilan implementasi program Upsus sebesar 
26 persen. Berdasarkan hasil uji deskripsi statistik diketahui bahwa dukungan sosial masuk kategori cukup baik. Hal ini menunjukkan bahwa kesediaan orang-orang untuk membantu, mendorong, dan menjaga agar program Upsus berjalan cukup baik. Sedangkan dukungan fisik masuk kategori baik. Dukungan fisik berkaitan dengan aksesibilitas dan kondisi lahan pertanian. Artinya akses menuju lahan pertanian cukup mudah dijangkau dan kondisi lahan pertanian yang ada di Kabupaten Banyumas juga subur. Hasil penelitian ini mendukung penelitian yang dilakukan oleh Trisnawati (2016) bahwa keberhasilan implementasi dipengaruhi oleh daya dukung lingkungan.

\section{Pengaruh Respon Kelompok Sasaran, Kemampuan Organisasi Pelaksana, dan Daya Dukung Lingkungan terhadap Keberhasilan Implementasi}

Hasil penelitian menunjukkan bahwa secara bersama-sama respon kelompok sasaran, kemampuan organisasi, dan daya dukung lingkungan berpengaruh secara positif dan signifikan terhadap keberhasilan implementasi program upsus di Kabupaten Banyumas. Secara bersamasama variabel-variabel tersebut mampu menjelaskan keberhasilan implementasi sebesar 51,4 persen. Artinya ketiga variabel yang diteliti mampu menjelaskan keberhasilan setengah dari faktor-faktor yang mendukung keberhasilan implementasi.

\section{KESIMPULAN}

Terdapat pengaruh yang positif dan signifikan antara Respon Kelompok Sasaran (X1) terhadap Keberhasilan Implementasi (Y) Program Upaya Khusus Peningkatan Produksi Padi di Kabupaten Banyumas. Ada pengaruh yang positif dan signifikan antara Kemampuan Organisasi Pelaksana (X2) terhadap Keberhasilan Implementasi (Y) Program Upaya Khusus Peningkatan Produksi Padi di Kabupaten Banyumas. Ada pengaruh yang positif dan signifikan antara Daya Dukung Lingkungan (X3) terhadap Keberhasilan Implementasi (Y) Program Upaya Khusus Peningkatan Produksi Padi di Kabupaten Banyumas. Ada pengaruh yang positif dan signifikan secara bersama-sama antara Respon Kelompok Sasaran (X1), Kemampuan Organisasi Pelaksana (X2), dan Daya Dukung Lingkungan (X3) terhadap Keberhasilan Implementasi (Y) Program Upaya Khusus Peningkatan Produksi Padi di Kabupaten Banyumas.

\section{Saran}

Implementasi Progam Upaya Khusus Peningkatan Produksi Padi di Kabupaten Banyumas telah berhasil dengan baik namun belum seratus persen, untuk itu masih perlu dilakukan pembenahan pada tingkat gapoktan dan poktan. Kesiapan gapoktan dalam menerima program-program petanian akan sangat berpengaruh terhadap keberhasilan implementasi program petanian.

Respon kelompok sasaran mempengaruhi keberhasilan implementasi program yang berarti perlu meningkatkan respon kelompok sasaran sehingga keberhasilan implementasi 
lebih baik. Sosialisasi program upsus harus lebih luas sehingga pengetahuan yang dimiliki oleh kelompok sasaran akan maksud dan tujuan program lebih jelas. Dengan pengetahuan dan pemahaman yang jelas maka kelompok sasaran akan memberikan respon yang positif. Selain itu, dengan pemahaman yang jelas mengenai program diharapkan partisipasi dan kesadaran kelompok sasaran semakin tinggi.

Kemampuan organisasi pelaksana mempengaruhi keberhasilan implementasi program upaya peningkatan produksi padi di Kabupaten Banyumas yang berarti perlu meningkatkan kemampuan organisasi pelaksana untuk meningkatkan keberhasilan implementasi program. Diklat dan pelatihan teknis yang diberikan kepada babinsa dan penyuluh bertujuan untuk meningkatkan kemampuan pelaksana dalam menghadapi pemasalah di lapangan. Koordinasi pelaksanaan juga harus jelas antara penyuluh dan babinsa karena kedua pelaksana ini memegang peran sebagai pengawal program upaya khusus.

Daya dukung lingkungan berpengaruh terhadap keberhasilan implementasi yang berarti untuk meningkatkan keberhasilan implementasi perlu untuk memperhatikan daya dukung lingkungan. Perlu memberikan pemahaman kepada masyarakat luas agar program ini mendapatkan dukungan dan tanggapan yang positif. Selain itu, komitmen dari pemerintah juga sangat diperlukan untuk mencapai keberhasilan implementasi. Komitmen pemerintah dibuktikan dengan adanya dukungan peraturan yang mungkin dibuat sesuai dengan karakteristik daerahnya sebagai pendamping peraturan dari peraturan yang lebih tinggi.

\section{DAFTAR PUSTAKA}

Budiani, Ni Wayan. 2007. Efektivitas Program Penanggulangan Pengangguran Karang Taruna "Eka Taruna Bhakti" Desa Sumerta Kelod Kecamatan Denpasar Timur Kota Denpasar. Jurnal ekonomi dan Sosial, Input. Vol 2 No. 1.

Daryanto, Arief. 2016. "Memposisikan secara Tepat Pembangunan Pertanian dalam Perspektif Pembangunan Nasional," Forum Pascasarjana, pp. 26-46.

Hjern, Benny, Hanf, Kenneth and Potter, David. 1978. "Local Networks of Manpower Training in the Federal Republik of Germany and Sweden". Interorganizational Policy Making: Limits to Coordination and Central Control. London: Sage.

Khariza, Hubaib Alif. 2015. "Program Jaminan Kesehatan Nasional: Studi Deskriptif tentang Faktor-faktor yang dapat Mempengaruhi Keberhasilan Implementasi Program Jaminan Kesehatan Nasional di Rumah Sakit Jiwa Menur Surabaya", Kebijakan dan Manajemen Publik, Vol. 3, No.1.

Nasila, Jans Wilianto. 2014. "Efektivitas Program Daerah Pemberdayaan Masyarakat (PDPM), Studi tentang Penanggulangan Kemiskinan di Kelurahan Mamboro Kecamatan Palu Utara Kota Palu", Jurnal Academica Fisip Unlad. Vol. 06. No. 02.

Nurharjadmo, Wahyu. "Evaluasi Implementasi Kebijakan Pendidikan Sistem Ganda di Sekolah Kejuruan", Spirit Publik, Vol.4 No.2 :215-228. 
Peter dan deLeon, Linda. 2004. "What Ever Happended to Policy Implementation? An Alternative Approach", Journal of Public Administration research and Theory, Vol. 12, No.4: 476-492.

Rindayani, Wiwiek; Sanin, Bunasor; Hutagaol, H. Parulian; dan Siregar, Hermanto. 2008. "Peran Pemerintah dalam Meningkatkan Ketahanan Pangan di Provinsi Jawa Barat Era Desentralisasi Fiskal: Analisis Simulasi Kebijakan," Forum Pascasarjana, Vol.31 No. 4, pp.251-267.

Smith, Thomas. B. 1973, The Policy Implementation Process, Elsevier Scientific Company, Policy Science 4 (1973), pp.197-209, Amsterdam.

Yus, Hendara. 2011. "Efektivitas Pelaksanaan Program TNI Manunggal Membangun Desa oleh Kodim 0609 Kab. Bandung terhadap Kesiapan Pertahanan Wilayah (Studi di Desa Tenjolaya Kecamatan Cicalengka Kabupaten Bandung)", Tesis. Universitas Gadjah Mada. 